\title{
Epidemiology and pathophysiologic insights of coronary atherosclerosis relevant for contemporary non-invasive imaging
}

\author{
Giancarlo Casolo ${ }^{1}$, Jacopo Del Meglio ${ }^{1}$, Carlo Tessa ${ }^{2}$ \\ ${ }^{1}$ Cardiology Department, Versilia Hospital, Lido di Camaiore, Italy; ${ }^{2}$ Radiology Department, Versilia Hospital, Lido di Camaiore, Italy \\ Contributions: (I) Conception and design: All authors; (II) Administrative support: All authors; (III) Provision of study materials or patients: None; \\ (IV) Collection and assembly of data: None; (V) Data analysis and interpretation: None; (VI) Manuscript writing: All authors; (VII) Final approval of \\ manuscript: All authors. \\ Correspondence to: Giancarlo Casolo, MD, PhD, FACC. Department of Cardiology, Versilia Hospital, Via Aurelia 335, Lido di Camaiore, LU, Italy. \\ Email: casolo@virgilio.it.
}

\begin{abstract}
In the past few years significant changes have taken place in the diagnostic and therapeutic approach to patients with coronary artery disease (CAD) and/or ischemic heart disease (IHD). New discoveries about the development and progression of coronary atherosclerosis have changed the clinical landscape. At the same time a marked decrease in cardiovascular (CV) mortality and CAD incidence have been observed in many Countries but particularly in the most industrialized ones. This fall has been also observed in the incidence of stroke, sudden death, myocardial ischemia, myocardial infarction (MI), and prevalence of CAD. As a consequence, an increasing number of patients with chest pain exhibits nonsignificant stenosis at both invasive and non-invasive coronary angiography and the rate of coronary vessels revascularizations has greatly reduced. Coronary atherosclerosis and its characteristics have shown to be both diagnostic and therapeutic targets beyond obstructive CAD. The decreased prevalence of CAD in the general population has modified the pre-test probability (PTP) of disease. In this landscape the conventional stress imaging tests appear to have limited accuracy making the diagnosis of obstructive CAD very challenging. These diagnostic tests have been introduced and tested in a population with a much higher probability of disease and therefore the contemporary accuracy of these old tests appear much lower than in the past. In addition, in the past few years the relevance of the traditional ischemia guided coronary intervention strategy has been questioned. Given the low CV events granted by an optimal medical therapy in CAD the major attention has been directed on detecting coronary atherosclerosis. The earlier the better. At the same time, a growing number of data from clinical studies have shown a significant prognostic role for non-obstructive $\mathrm{CAD}$ and coronary atherosclerosis. All these facts have shifted the clinicians' attention from the functional evaluation of the coronary circulation to the anatomic burden of disease.
\end{abstract}

Keywords: Coronary artery disease (CAD); atherosclerosis; cardiovascular imaging (CV imaging)

Submitted Feb 03, 2020. Accepted for publication Aug 17, 2020.

doi: $10.21037 / \mathrm{cdt}-20-157$

View this article at: http://dx.doi.org/10.21037/cdt-20-157

\section{Introduction}

Coronary atherosclerosis is the most common disease of the coronary arteries. Its natural history as well as the pathologic mechanisms by which the disease progresses and eventually translates in clinical events has been extensively studied in the past and recent years. The results of these efforts have greatly increased our knowledge and new concepts have been developed over the years and translated in clinical practice (1-7).

In the past few decades cardiovascular (CV) mortality, myocardial infarction (MI) and stroke incidence, severity of coronary atherosclerosis have greatly decreased thus changing the prognostic and diagnostic landscape of 
patients with suspected or confirmed CAD (8-15). Coronary atherosclerosis is the main cause for ischemic heart disease (IHD), although not the only one. The main attention of the professional medical community has been directed to detect and treat the so called "significant coronary stenosis". In the traditional model of care myocardial ischemia was the main diagnostic and therapeutic target. Obstructive CAD was considered the most important manifestation of atherosclerosis for prognostic purposes representing the main cause for ischemia. In the past few years, the above mentioned changes in $\mathrm{CV}$ epidemiology, have translated in a lower than expected probability of obstructive CAD $(16,17)$. Traditional diagnostic tools such as the treadmill or bicycle stress test but even other imaging stress tests have shown to be less accurate than in the past in detecting ischemia and CAD $(18,19)$. The need for a very accurate technique to detect obstructive $\mathrm{CAD}$ has thus emerged as an important need in clinical practice.

At the same time a growing evidence from large clinical trials indicate that an ischemia driven diagnostic and therapeutic strategy may be less relevant than the detection of the extent and quality of coronary atherosclerosis even when there are no flow-limiting coronary stenosis. Many evidences have shifted the attention to non-obstructive CAD and, more broadly speaking, to coronary atherosclerosis and its burden $(20,21)$. This knowledge has boosted the attention to the detection of coronary atherosclerosis, its extent, but also to the plaque composition of the detected lesions (22-25).

\section{Coronary atherosclerosis}

Once viewed as the result of a degenerative disease of the arterial wall, atherosclerosis is nowadays considered inflammatory in its origin $(1,26)$. Several pathways involved in both innate and adapted immunity have been related to atherosclerosis as well as the loss of regulatory mechanisms involved in cell growth and differentiation. Thus, a combination of factors involving the immunological system, inflammation and the modulation of cell growth and differentiation all play a significant role in the development of atherosclerosis, its progression and clinical manifestations (27-34).

The atherosclerotic plaque forms in the intima layer of the vessels. In the early stage low-density lipoprotein (LDL) particles accumulate in the intima causing a proinflammatory and immunogenic stimulus. The subsequent immune response takes place within the arterial wall with multiple kind of cells involved. The atherosclerotic plaque is the result of opposing mechanisms involving both inflammatory and reparative processes. Once established, atherosclerotic plaques progress by continued accumulation of lipid and the appearance of foam cells. Resident smooth muscle cells participate in this process and elaborate extracellular matrix macromolecules that represent a major component of the atherosclerotic plaques. Accumulation of lipids, dead cells, proteoglycans and glycosaminoglycans produced by the resident and recruited smooth muscle cells participate to the plaque growth and finally to the necrotic core. Once established the disease progresses and the lesions expand outward radially maintaining the caliber of the vessel. Calcium deposits appear and are either associated with plaque instability and complications or stabilization. The coronary plaques may grow leading eventually to flow limiting stenosis or undergo to complications such as plaque rupture or erosion. Experimental data suggest that the complications of atherosclerotic plaques may contribute to their growth trough a process of healing $(35,36)$.

With the advent of ICA and percutaneous coronary intervention by angioplasty (PCI) or by pass surgery (BPAC) coronary atherosclerosis has received major attention. The demonstration that treating obstructive CAD of the epicardial vessels could improve the prognosis both in STEMI and NSTEMI patients as well as in chronic angina boosted the widespread adoption of direct coronary interventions. Both PCI and BPAC nowadays represent the standard of care in many clinical settings.

\section{Definitions}

CAD should be clearly differentiated from IHD, the latter being the results of both a reversible or irreversible myocardial damage. Typically, AMI is a manifestation of CAD but a MI can be the result of many other conditions and can be observed even when CAD is totally absent. The same is true for myocardial ischemia. On the other end CAD should not be a synonymous of coronary atherosclerosis. As a matter of fact the coronary arteries may be affected by several different conditions without any apparent atherosclerotic lesion. Finally, chronic IHD should be a clinical definition reserved to include patients who have IHD except for those with acute coronary syndromes (ACS). Patients with known manifestations of CAD of any type belong to this definition. Often unfortunately CAD, coronary atherosclerosis, IHD, are used interchangeably. This indistinct use of terms can determine some unwanted 
consequences.

The recent European Society of Cardiology (ESC) guidelines have coined the term of chronic coronary syndromes (CCS) in the attempt to embrace several different conditions other than ACS (37). As a matter of fact CCS include six clinical scenario: (I) patients with suspected CAD and 'stable' anginal symptoms, and/ or dyspnea; (II) patients with new onset of HF or LV dysfunction and suspected CAD; (III) asymptomatic and symptomatic patients with stabilized symptoms 1 year after initial diagnosis or revascularization; (V) patients with angina and suspected vasospastic or microvascular disease; (VI) asymptomatic subjects in whom CAD is detected at screening. This definition has the merit of offering a more complete classification of conditions than before. If this new definition will offer advantages have to prove its soundness in clinical practice.

\section{Epidemiology of coronary artery disease (CAD)}

An initial decline in CV mortality in the US was first reported in the early 1970s. However a well recognized negative trend was universally recognized only in 1978 . This decline have continued and observed in all the regions of the world although more pronounced in the high income countries (8). In Netherlands the decline from 1980 to 2009 has been around $70 \%$ while in UK and Ireland more than 60\% (13). Between 1990 and 2013 CVD death rates in England declined by $52 \%$, coronary heart disease (CHD) by $60 \%$, and stroke by $46 \%$ (38). Sudden death, a common first manifestation of CAD, acute myocardial infarction (AMI), stroke all have significantly decreased $(13,15,39,40)$. The decline in CV mortality has been paralleled by a decrease in the incidence and related mortality of AMI, stroke and more broadly of all the clinically relevant atherosclerotic vascular diseases (i.e., carotid vessel disease, peripheral artery disease). The death rate for MI in US between 1970 and 2010 has fallen from $16 \%$ to $1.9 \%$ in patients $<65$ years and from $37.8 \%$ to $7.6 \%$ in those older than 65 (41). At the same time due to improved survival of patients with $\mathrm{CV}$ events, the prevalence of disease has been described either unchanged or increased (42). Therefore while patients live longer and the burden of new patients with atherosclerotic complications decrease it is increasingly common to face subjects with an history of stroke, MI or heart failure due to previous CV events.

The observed decrease in CV events in the general population has been recorded almost universally and applies to all the most common complications of atherosclerotic vessels disease. Initially observed for ST elevation -MI (whose incidence is decreasing by $10 \%$ yearly) more recently has been also observed for NST elevation- MI (14). The hospitalizations for acute MI has also fallen from 53 to 25 cases $\times 10,000$ individuals in US between 1970 and 2010 (41). This decrease in new cases of AMI has been so sharp that some Authors have wondered if this condition is going to disappear (43).

Interestingly the burden of coronary atherosclerosis also seems to ease. In the Copenhagen City Heart Study 11223 Pts were investigated by ICA from 1998 to 2009 for suspected CAD. Obstructive CAD became less common in men but particularly in woman over time. In 2008, around $70 \%$ of women and $40 \%$ of men who were referred to ICA for stable angina did not have a flow limiting stenosis compared to 55 and $20 \%$ in the year 2000 (44). The study showed that the change was progressive and was continuing.

Not only the angiographic findings seem to have changed (at least for patients with stable angina referred for ICA) but also there have been changes in the histologic pattern of those lesions causing ACS. Clinical and experimental studies have shown that the most common morphology of a culprit lesion causing ACS is a plaque rupture with exposure of thrombogenic debris. However, another cause for thrombosis complicating an atherosclerotic lesion is represented by a plaque erosion without rupture. The first once considered far more common than the last (36). The most recent studies indicate that the culprit lesion determining ACS underlying a coronary occlusion less commonly is a ruptured plaque (45) while the main mechanism nowadays is represented by a plaque erosion.

Serial studies have shown that statin treatment reduce lipid content and increase the collagen content of the atherosclerotic lesions both related to plaque stabilization and decreased risk of acute events (46). Also dietary habits influence the plaque composition and the same is believed for smoking (47). The improvements in risk factors control may therefore cause detectable morphologic changes that may translate in different clinical manifestations of the disease. A significant modification in the risk profile of patients including the use of medications to treat hypertension or dyslipidemia is paralleled by fewer events. The underlying mechanisms is a reduction in the presence of atherosclerosis and a more favorable composition of the plaques. The Athero Express data collected by the Dutch biobank have shown a clear change in the carotid plaque composition from patients with CV events since 2002 (48). 
The morphology of the new plaques collected from patients undergoing endarterectomy showed in time progressively less hemorrhagic complications, calcifications, and evidence for inflammation. The lipid core of the plaques also decreased significantly. These changes have been observed in both patients with or without symptoms indicating a generalized temporal shift from the expression of unstable to more stable plaque characteristics.

\section{What are the causes for the decline in CV disease burden?}

As above reported the observed decline in $\mathrm{CV}$ mortality and $\mathrm{CV}$ events has been observed in all the high-income countries and some regions of the world. This positive trend started several decades ago and it is still ongoing $(8,13)$. It is generally accepted that these benefits should be largely due to improved control of risk factors (smoke, unhealthy diet, physical activity, etc..) and pharmacological interventions (particularly statins, and anti-hypertensive drugs) (49-51). However, a significant role may be related to the policies directed to decrease the unnecessary use of alimentary additive such as trans-saturated fatty acids that have been linked to higher CV mortality (52).

By using the IMPACT mortality model it has been shown that that $50-75 \%$ of the decrease in cardiac deaths can be attributed to improvements in the major risk factors (53). The remaining percentage of the decreased mortality is usually explained by the widespread use of drug therapy to lower blood pressure and cholesterol levels. Although improvement in medical care appear to be of great importance to explain the sharp decrease in $\mathrm{CV}$ death and events the relevance of PCI or BPAC therapies are considered to contribute marginally to the global $\mathrm{CV}$ risk reduction (54).

\section{Practical effects of the observed changes}

The observed change in epidemiology of CAD has several important consequences in clinical practice.

\section{Cardiovascular Risk Prediction}

In the past years in order to establish a preventive program to limit $\mathrm{CV}$ diseases and their consequences several scores have been used to guide the clinical choices. An interesting example are the SCORE risk charts recommended by the ESC for identifying patients at different $\mathrm{CV}$ risk (55). These charts have been developed to assess the individual risk of $\mathrm{CV}$ death of individuals apparently free from $\mathrm{CV}$ diseases and are based upon age, sex, blood cholesterol, blood pressure, and smoking habits. As underlined by Mortensen and Falk (56) the SCORE mortality from CV disease is now so low in many countries that the SCORE-based statin therapy soon might be history in these countries despite high CV morbidity and treatment costs. In spite of the availability of different charts for different geographic areas and efforts to recalibrate the SCORE-prediction model by using administrative data of mortality it is likely that new approaches will be necessary to help Physicians to guide primary prevention.

This is a classical example of how difficult may be to predict $\mathrm{CV}$ events in this era of low probability of disease. The mortality risk for $\mathrm{CV}$ causes predicted for the general population is currently very close to that predicted for patients who recovered from a $\mathrm{CV}$ event. This makes very complicate to differentiate primary from secondary prevention and as a matter of fact the most recent European Society of Cardiology (ESC) Guidelines on Cardiovascular Disease Prevention in Clinical Practice treat cardiovascular risk as a continuum rather than dealing with two different conditions of risk. The clinical focus nowadays is being shifted more and more on the reduction and prevention of new $\mathrm{CV}$ events rather on mortality reduction. Yet the SCORE charts are still recommended to establish the individual $\mathrm{CV}$ risk.

\section{Diagnosis of obstructive CAD}

There have been significant changes in time in the approach to coronary atherosclerosis. The clinicians' attention has been mainly focused on significant CAD (i.e., obstructive disease), its detection and treatment. Although many $\mathrm{CV}$ events will be determined by the complications of plaques determining significant coronary stenosis, a large number (apparently the majority) of events can be attributed to nonsignificant lesions that rapidly progress and promote an acute thrombosis (57-59). Recent in-vivo data confirmed that the progression of coronary plaques participate in the growth of the lesions through a healing process that may or not precede a new clinically meaningful event $(60,61)$. In this view, the presence of one or more flow limiting stenosis in a patient represents the result of a progression of a disease that is not confined to a specific vascular territory. A specific attention only to these lesions may decrease the attention to less significant and nonobstructive plaques 
yet able to promote a catastrophic complication if not adequately treated.

The speed of progression and probability of complication of any lesion are the most likely drivers for the appearance of symptoms and development of an ACS. The major difference between an arterial tree with or without flow limiting stenosis is the probability of a lesion to complicate and cause a coronary thrombosis. Thus, the description of any plaque burden rather than the simple search for a flow limiting stenosis represents a more meaningful approach.

Traditionally an ischemia driven approach in detecting a significant $\mathrm{CAD}$ has been recommended and implemented in clinical practice. The assumption is that the presence of a flow limiting stenosis causes myocardial ischemia and this is prognostically important. The presence and severity of ischemia detected by any diagnostic tool has therefore guided the therapeutic choices to improve symptoms and prognosis. This premise has been challenged by several observations and it is currently underway an international investigation that will hopefully establish whether an ischemia driven strategy may or not improve the outcome of CAD patients (62). Interestingly the enrolment of this study (ISCHEMIA: International Study of Comparative Health Effectiveness With Medical and Invasive Approaches trial) which originally should have included patients with moderate to severe ischemia also randomized a number of patients with weak or no ischemia, apparently because of a paucity of patients with the wanted amount of ischemia (63). In an accompanying editorial Raymond Gibbons acknowledges that in the contemporary era these patients are less common as in the past (64).

Data from the landmark COURAGE study have shown that a conservative approach is not inferior to an invasive approach in CAD patients with evidence of even large ischemic areas (65). If the diagnostic goal is to detect obstructive CAD, and if the demonstration of ischemia should remain the standard of care, we may note that in the contemporary era the probability of a positive stress test result and its severity has changed. In other words, patients with either established CAD or suspected CAD less commonly exhibit a positive stress study with respect to the past.

By analyzing 39,515 diagnostic patients undergoing stress-rest MPS between 1991 and 2009 at the CedarsSinai Medical Center Rozanski and coworkers have found a marked decrease in time of the frequency and severity of abnormal tests raising the issue of more effective strategies in a contemporary population of patients at lower than expected CV risk (18). Similar results have been observed for stress echocardiography (66). Additional observation from other centers such as the Mayo Clinic experience suggests a significant decrease in patients with or without a previous MI $(67,68)$. Not surprisingly also the temporal trend in the use of coronary angiography and coronary revascularization rate paralleled this change (69).

\section{The contemporary landscape}

A large amount of evidence describes a significant change in the contemporary prevalence of obstructive CAD in the general population. As a consequence, the burden of disease is often overestimated by old evidences. The recent 2019 ESC guidelines for the diagnosis and management of chronic coronary syndromes have recognized this observation (37). The previous 2013 ESC guidelines on the management of stable CAD posed a major attention to prognosis rather than to the correct diagnosis (70). The first step of the strategy was directed to the determination of the pre-test probability (PTP) of CAD. Patients with an intermediate PTP of disease could then be evaluated for prognosis while those with a low PTP $(<15 \%)$ could even be excluded by further investigations. This group could nevertheless harbor patients with obstructive disease but no other test was recommended. A major diagnostic role was instead attributed to the ergometric/treadmill stress test although its sensitivity is known to be very low in detecting CAD. In 2013 the PTP of obstructive coronary disease was recommended by using an updated version of the old Diamond and Forrester table (16). Data from was subsequent investigations have highlighted a lower than expected probability of disease in these patients. The very recent 2019 ESC guidelines for the diagnosis and management of chronic coronary syndromes have introduced some major changes. As the observed prevalence of obstructive $\mathrm{CAD}$ is nowadays much lower than in the past a new version of the PTP of disease based on the description of symptoms, age and sex has been updated (71) and incorporated in the guidelines. As an example, a 65-year-old man with typical angina in this probability frame has a PTP of disease of $46 \%$ compared to the $94 \%$ suggested by the old original Diamond and Forrester chart (72).

The following step recommended by the guidelines is to use the most appropriate test based upon the clinical likelihood of significant disease. The clinical likelihood enrich the PTP incorporating a constellation of aspects that the simple PTP tables do not include (i.e., CV risk 
factors, ECG abnormalities, LV dysfunction, CKD, etc.). At any level of PTP, the clinical likelihood of disease (not only the PTP) should hence guide the diagnostic strategy. The downstream diagnostic tests are recommended in any patient in whom an obstructive CAD cannot be excluded by clinical means, and are offered based upon local expertise, availability and patients' factors that may influence the test performance. The suggested behavior focusses on the observed epidemiological changes and resulting diagnostic difficulties on one side and the need for an individualized approach based upon the clinical needs on the other.

\section{The modern diagnostic challenges}

Several diagnostic tools are currently used to identify chest pain patients with significant $\mathrm{CAD}$ and to detect a flow limiting stenosis. It is intuitive that a significant fall in the target of any test of ischemia is a direct consequence of a marked decrease in the probability of disease (i.e., presence of flow limiting stenosis). The already revised Diamond and Forrester classification of CAD probability proposed by the 2013 ESC guidelines on the management of chronic angina have shown to overestimate the probability of disease. New probability scores for the prediction of significant CAD have been proposed (73-76). As a matter of fact a contemporary male patient 65 -year-old with typical angina has a $44 \%$ probability of significant CAD while the probability drops below $20 \%$ for a female patient with the same clinical features.

It is well known that the diagnostic accuracy of any diagnostic test is strictly dependent on the population studied. The Bayes' rule implies that the result of any test is influenced by the PTP of the disease studied. The accuracy may thus greatly vary depending on the likelihood of the abnormality the test is investigating.

As an example, tests such as a stress SPECT-MPI or stress ECHO typically offer a diagnostic accuracy around $70-80 \%$. However, these tests were introduced and implemented in clinical practice when the probability of obstructive CAD in the population with atypical chest pain ranged depending on age, from $30 \%$ to $70 \%$. In the contemporary era the same population has a probability ranging from $4-34 \%$. When the prevalence falls it is unavoidable that the accuracy of any test falls due to a loss of both sensitivity and specificity. Therefore, by applying the stress imaging tests tested in the past panorama one should expect a significant increase of false negative, and perhaps also of false positive, tests.
In the EVINCI trial which compared the accuracy of stress SPECT-MPI, stress-ECHO, stress-CMR and Computed Tomography Coronary Angiography (CTCA) $v s$. ICA the best technique to detect a flow limiting stenosis resulted to be CTCA (19). In this study the population enrolled that was planned to be at intermediate probability of disease showed only a $29 \%$ prevalence of significant CAD. In this condition CTCA has shown to have a superior accuracy $(91 \%)$ with an almost $100 \%$ NPV and a $83 \%$ of PPV, much superior to any other technique.

In spite of these results in the clinical arena stress imaging tests, particularly MPI SPECT (dypiridamole, adenosine, exercise) and stress echo are commonly still used all over the world and often interchangeably.

Recent efforts have been spent to identify the best non invasive test to detect a significant CAD in the contemporary landscape. In a large metanalysis including 28 664 patients from 132 studies that used ICA as a reference and 4,131 from 23 studies using FFR, Knuuti et al. have estimated the PTP when a positive or negative test result can confidently rule-in or rule-out a significant CAD (77). They assembled a model incorporating for each test the reliability of a positive or negative test for any pre - test probability. Interestingly they showed that even ICA does not perform optimally when ICA-FFR is used as a reference standard. However, when ICA is used to evaluate CAD, stress CMR, PET, and CTCA more reliably detect or rule out a significant disease.

By changing either the probability of disease, and its severity in causing ischemia, two major issues have been raised:

* The need for new evidences to support the use of any diagnostic test in the contemporary era;

* A progressive loss of importance of ischemia for prognostic stratification.

\section{New evidences}

A consequence of the above described picture raises the need for new evidences to support the use of any diagnostic test to detect ischemia and significant CAD. Myocardial ischemia may be caused by several different mechanisms (78) and should not be considered as the only manifestation of a flow limiting stenosis. The most recent investigations designed to establish the role of the different methods to detect obstructive CAD in patients with chest pain or equivalent symptoms have all pointed out the best accuracy of CCT over other noninvasive tests. The best 
demonstration of the translation into clinical practice of these data are the new recommendations for the diagnosis of the Chronic Coronary Syndromes of the ESC (37). The bicycle/treadmill stress test is now suggested as a tool to evaluate the functional capacity while has disappeared as a diagnostic tool. Functional test based on inducible ischemia still have a significant role in spite of the sobering results offered by some studies. It is nevertheless very important that the new ESC guidelines stress the need for a new diagnostic and prognostic framework due the relevant secular trend for CAD observed in the population.

\section{The new landscape: anatomy is more important than ischemia}

All the best evidences and results of trial and tests using any ischemia - driven target for diagnosis and prognosis are old and outdated. It is hard to think that, given all the major changes observed, the result of an imaging test may preserve its prognostic meaning. The relevance of ischemia itself as a major component of a prognostic model has been questioned in the past few years and is under investigation $(62,79)$.

The PRoMISE trial and the SCOTHeart trial, although different in design and organization both have showed that by applying an anatomy based prognostic model the short term results can even be better than an ischemia based approach $(80,81)$. By prolonging the follow up of these studies the information offered by CCT about coronary anatomy have shown the superiority over other approaches $(21,82)$.

It is now recognized that by detecting coronary atherosclerosis it is possible to significantly improve the survival and decrease the events of patients with chest pain and suspected CAD. By implementing the preventive measures known to influence the progression of atherosclerotic lesions it has been observed a significantly lower rate of death from coronary heart disease or nonfatal MI at 5 years (21). This result is the best demonstration of previous observational data showing a prognostic gain by the information obtained by using coronary anatomy as described by CTCA to select those patients that may most benefit from the use of the preventive drugs (83-87).

\section{The search for the vulnerable plaque}

Several efforts have been taken to identify those lesions that will complicate and promote an ACS. The association of certain plaque features with their rupture has promoted several investigations. Plaques with a thin cap fibro- atheroma (TCFA) have been associated with plaque instability (88-91). The most famous study investigating in-vivo the proposed association was the PROSPECT trial that showed that the risk of events associated with the TCFA was very low (27). The VIVA study showed similar results (92). Further studies using CTCA have shown that some features, and particularly a low density attenuation or a vessel remodeling can predict future plaques complications. Taken together the best evidence suggests that both the atherosclerotic burden by itself and some features of the plaques (i.e., the positive remodeling and/or low attenuation) can identify lesions more prone to complications (93).

\section{The fractional flow reserve (FFR)}

Several studies have shown that FFR is superior to the conventional angiographic assessment of coronary lesions to evaluate their ability to cause ischemia $(94,95)$. The use of FFR to guide coronary revascularization has been shown to improve clinical outcomes (96). In recent years this parameter can be derived also by using conventional CTCA, computational fluid dynamics algorithms and simulated maximal coronary hyperemia (97). FFR-CT has been validated against invasively measured FFR as a reference standard $(98,99)$ and shown to be clinically useful $(100)$. Thus, FFR can be also evaluated by non-invasive means.

The clinical use of this parameter is however recommended by the ESC guidelines on coronary revascularization to evaluate intermediate lesions (typically around $40-90 \%$ stenosis) to establish the need of a PCI when evidence of ischemia is not available (Class I, level of evidence A) or in multivessel disease undergoing ICA to guide PCI (Class IIa, level of evidence B) (101).

\section{Conclusions}

Several changes have taken place in the conceptual framework of Physicians involved in the care of patients with suspected or recognized CAD. CV mortality has significantly dropped in the past years. A major decrease in the incidence of obstructive CAD has paralleled this survival benefit but has determined some major diagnostic challenges. The decreased probability of disease has made difficult to both predict and diagnose CAD. The diagnostic panorama that was once mainly dominated by the search for ischemia has been replaced by the quest for the presence and extent of coronary atherosclerosis. 
Significant prognostic improvements have been obtained in patients presenting with chest pain by focusing the attention to atherosclerosis rather than (or at least together) to significant coronary stenosis. While the prognostic role of myocardial ischemia has been challenged, the prompt initiation of preventive measures in patients with documented coronary atherosclerosis has determined in fewer CV events.

In the current era the most effective diagnostic technique for obtaining a survival and/or an uneventful course in patients with suspected CAD appear to be CTCA. Stress imaging tests may be nonetheless very useful for a further prognostic assessment. The detection of intermediate to significant obstructive lesions may prompt further investigations to establish their ability to determine ischemia. These lesions carry a significant risk of events well beyond those of lesser severity although even small amount of coronary atherosclerosis confers a risk of developing $\mathrm{CV}$ events. The depiction of the presence, extent, severity, and quality of coronary atherosclerosis appear to be the main diagnostic target of contemporary imaging in patients with suspected or confirmed CAD or IHD.

\section{Acknowledgments}

We are indebted to ML. Canale, E. Ferrali, A.Lilli, F.De Caro and $\mathrm{R}$ Poddighe for their support in writing and reviewing the manuscript.

Funding: None.

\section{Footnote}

Provenance and Peer Review: This article was commissioned by the Guest Editor (Filippo Cademartiri) for the series "Clinical Impact of Cardiac CT in Clinical Practice" published in Cardiovascular Diagnosis and Therapy. The article was sent for external peer review organized by the Guest Editor and the editorial office.

Conflicts of Interest: All authors have completed the ICMJE uniform disclosure form (available at http://dx. doi. org/10. 21037/cdt-20-157). The series "Clinical Impact of Cardiac CT in Clinical Practice" was commissioned by the editorial office without any funding or sponsorship. The authors have no other conflicts of interest to declare.

Ethical Statement: The authors are accountable for all aspects of the work in ensuring that questions related to the accuracy or integrity of any part of the work are appropriately investigated and resolved.

Open Access Statement: This is an Open Access article distributed in accordance with the Creative Commons Attribution-NonCommercial-NoDerivs 4.0 International License (CC BY-NC-ND 4.0), which permits the noncommercial replication and distribution of the article with the strict proviso that no changes or edits are made and the original work is properly cited (including links to both the formal publication through the relevant DOI and the license). See: https://creativecommons.org/licenses/by-nc-nd/4.0/.

\section{References}

1. Hansson GK. Inflammation, atherosclerosis and coronary artery disease. N Engl J Med 2005;352:1685-95.

2. Glaser R, Selzer F, Faxon DP, et al. Clinical progression of incidental asymptomatic lesions discovered during vessel coronary intervention. Circulation 2005;111:143-9.

3. Ahmadi A, Leipsic J, Blackstein R, et al. Do plaques rapidly progress prior to myocardial infarction? The interplay between plaque vulnerability and progression. Circ Res 2015;117:99-104.

4. Croce K, Libby P. Intertwining of thrombosis and inflammation in atherosclerosis. Curr Opin Hematol 2007:14;55-61.

5. Arbab-Zadeh A, Nakano M, Virmani R, et al. Acute coronary events. Circulation 2012;125:1147-56.

6. Libby P, Hansson GK. From local lipid storage to systemic inflammation. J Am Coll Cardiol 2019;74;1594-607.

7. Libby P, Pasterkamp G Crea F, et al. Reassessing the mechanisms of acute coronary syndromes. Circ Res 2019;124:150-60.

8. Mensah GA, Wei GS, Sorlie PD, et al. Decline in cardiovascular mortality. Possible causes and implications. Circ Res 2017;120:366-80.

9. GBD 2015 Mortality Causes of Death Collaborators. Global, regional, and national life expectancy, all-cause mortality, and cause-specific mortality for 249 causes of death, 1980-2015: a systematic analysis for the Global Burden of Disease Study 2015. Lancet 2016;388:1459-544.

10. Moran AE, Forouzanfar MH, Roth GA, et al. Temporal trends in ischemic heart disease mortality in 21 world regions, 1980 to 2010: the Global Burden of Disease 2010 study. Circulation 2014;129:1483-92.

11. Lozano R, Naghavi M, Foreman K, et al. Global and regional mortality from 235 causes of death for 20 
age groups in 1990 and 2010: a systematic analysis for the Global Burden of Disease Study 2010. Lancet 2012;380:2095-128.

12. Roth GA, Huffman MD, Moran AE, et al. Global and Regional Patterns in Cardiovascular Mortality From 1990 to 2013. Circulation 2015;132:1667-78.

13. Hartley A, Marshall DC, Salciccioli JD, et al. Trends in Mortality From Ischemic Heart Disease and Cerebrovascular Disease in Europe:1980 to 2009. Circulation 2016;133:1916-26.

14. Yeh RW, Sidney S, Chandra M, et al. Population trends in the incidence and outcomes of acute myocardial infarction. N Engl J Med 2010;362:2155-65.

15. Feigin VL, Mensah GA, Norrving B, et al. Atlas of the Global Burden of Stroke (1990-2013): The GBD 2013 Study. Neuroepidemiology 2015;45:230-6.

16. Genders TS, Steyerberg EW, Alkadhi H, et al. A clinical prediction rule for the diagnosis of coronary artery disease: validation, updating, and extension. Eur Heart J 2011;32:1316-30.

17. Cheng VY, Berman DS, Rozanski A, et al. Performance of the traditional age, sex, and angina typicalitybased approach for estimating pretest probability of angiographically significant coronary artery disease in patients undergoing coronary computed tomographic angiography: results from the multinational coronary CT angiography evaluation for clinical outcomes: an international multicenter registry (CONFIRM). Circulation 2011;124:2423-32.

18. Rozanski A, Gransar H, Hayes SW, et al. Temporal trends in the frequency of inducible myocardial ischemia during cardiac stress testing:1991 to 2009. J Am Coll Cardiol 2013;61:1054-65.

19. Neglia D, Rovai D, Caselli C, et al. Detection of Significant Coronary Artery Disease by Noninvasive Anatomical and Functional Imaging. Circ Cardiovasc Imaging 2015;8:e002179.

20. Mancini GBJ, Hartigan PM, Shaw LJ, et al. Predicting outcome in the COURAGE trial (Clinical Outcomes Utilizing Revascularization and Aggressive Drug Evaluation): coronary anatomy versus ischemia. JACC Cardiovasc Interv 2014;7:195-201.

21. SCOT-HEART Investigators, Newby DE, Adamson PD, et al. Coronary CT angiography and 5-year risk of myocardial infarction. N Engl J Med 2018;379:924-33.

22. Lee H, Yoon YE, Park JB, et al. The Incremental Prognostic Value of Cardiac Computed Tomography in Comparison with Single-Photon Emission Computed
Tomography in Patients with Suspected Coronary Artery Disease. PLoS One 2016;11:e0160188.

23. Bittencourt MS, Hulten E, Ghoshhajra B, et al. Prognostic Value of Nonobstructive and Obstructive Coronary Artery Disease Detected by Coronary Computed Tomography Angiography to Identify Cardiovascular Events. Circ Cardiovasc Imaging 2014;7:282-91.

24. Lin FY, Shaw LJ, Dunning AM, et al. Mortality Risk in Symptomatic Patients With Nonobstructive Coronary Artery Disease. J Am Coll Cardiol 2011;58:510-9.

25. Ahmadi A, Stone GW, Leipsic J, et al. Prognostic Determinants of Coronary Atherosclerosis in Stable Ischemic Heart Disease Anatomy, Physiology, or Morphology? Circ Res 2016;119:317-29.

26. Libby P, Ridker PM, Maseri A. Inflammation and Atherosclerosis. Circulation 2002;105:1135-43.

27. Stone GW, Maehara A, Lansky AJ, et al., PROSPECT Investigators. A prospective natural history study of coronary atherosclerosis. N Engl J Med 2011;364:226-35.

28. Ait-Oufella H, Salomon BL, Potteaux S, et al. Natural regulatory $T$ cells control the development of atherosclerosis in mice. Nat Med 2006;12:178-80.

29. Libby P, Loscalzo J, Ridker PM, et al. Inflammation, immunity, and infection in atherothrombosis: JACC Review Topic of the Week. J Am Coll Cardiol 2018;72:2071-81.

30. Jaiswal S, Natarajan P, Silver AJ, et al. Clonal hematopoiesis and risk of atherosclerotic cardiovascular disease. N Engl J Med 2017;377:111-21.

31. Wang W, Liu W, Fidler T, et al. Macrophage inflammation, erythrophagocytosis, and accelerated atherosclerosis in Jak2 V617F mice. Circ Res 2018;123:e35-47.

32. Libby P, Ebert B. CHIP (Clonal Hematopoiesis of Indeterminate Potential): potent and newly recognized contributor to cardiovascular risk. Circulation 2018;138:666-8.

33. Moore KJ, Koplev S, Fisher EA, et al. Macrophage trafficking, inflammatory resolution and genomics in atherosclerosis. J Am Coll Cardiol 2018;72:2181-97.

34. Abdolmaleki F, Gheibi Hayat SM, Bianconi V, et al. Atherosclerosis and immunity: A perspective. Trends Cardiovasc Med 2019;29:363-71.

35. Libby P, Buring JE, Badimon L, et al. Atherosclerosis. Nat Rev Dis Primers 2019 16;5:56.

36. Bentzon JF, Otsuka F, Virmani R, Falf E. Mechanisms of Plaque Formation and Rupture. Circ Res 2014;114:1852-66. 
37. Knuuti J, Wijns W, Saraste A, et al. ESC Guidelines for the diagnosis and management of chronic coronary syndromes. Eur Heart J 2020;41:407-77.

38. Bhatnagar P, Wickramasinghe K, Wilkins E, Townsend N. Trends in the epidemiology of cardiovascular disease in the UK. Heart 2016;102:1945-52.

39. Benjamin EJ, Muntner P, Alonso A, et al. Heart Disease and Stroke Statistics-2019 Update: A Report From the American Heart Association. Circulation 2019;139:e56-528.

40. Shuvy M, Qiu F, Lau G, et al. Temporal trends in sudden cardiac death in Ontario, Canada. Resuscitation 2019;136:1-7.

41. National Institutes of Health. Morbidity \& mortality: 2012 chart book on cardiovascular, lung, and blood diseases. NHLBI. (2012). Available online: https://www.nhlbi.nih. gov/files/docs/research/2012_ChartBook_508.pdf

42. Koch MB, Davidsen M, Andersen LV, et al. Increasing prevalence despite decreasing incidence of ischaemic heart disease and myocardial infarction. A national register based perspective in Denmark, 1980-2009. Eur J Prev Cardiol 2015;22:189-95.

43. Luepker RV, Berger AK. Is Acute Myocardial Infarction Disappearing? Circulation 2010;121:1280-2.

44. Jespersen L, Hvelplund A, Abildstrøm SZ, et al. Stable angina pectoris with no obstructive coronary artery disease is associated with increased risks of major adverse cardiovascular events. Eur Heart J 2012;33:734-44.

45. Pasterkamp G, den RuijterHM, Libby P. Temporal shifts in clinical presentation and underlying mechanisms of atherosclerotic disease. Nat Rev Cardiol 2017;14:21-9.

46. Libby, P. How does lipid lowering prevent coronary events? New insights from human imaging trials. Eur Heart J 2015;36:472-4.

47. Gonçalves I, Andersson Georgiadou E, Mattsson S, et al. Direct association between diet and the stability of human atherosclerotic plaque. Sci Rep 2015;5:15524.

48. van Lammeren GW, den Ruijter HM, Vrijenhoek JE, et al. Time-dependent changes in atherosclerotic plaque composition in patients undergoing carotid surgery. Circulation 2014;129:2269-76.

49. Ezzati M, Obermeyer Z, Tzoulaki I, et al. Contribution of risk factors and medical care to cardiovascular mortality trends. Nat Rev Cardiol 2015;12:508-30.

50. Wijeysundera HC, Machado M, Farahati F, et al. Association of temporal trends in risk factors and treatment uptake with coronary heart disease mortality, 1994-2005. JAMA 2010;303:1841-7.

51. Koopman C, Vaartjes I, van Dis I, et al. Explaining the Decline in Coronary Heart Disease Mortality in the Netherlands between 1997 and 2007. PLoS One 2016;11:e0166139.

52. de Souza RJ, Mente A, Maroleanu A, et al. Intake of saturated and trans unsaturated fatty acids and risk of all cause mortality, cardiovascular disease, and type 2 diabetes: systematic review and meta-analysis of observational studies. BMJ 2015;351:h3978.

53. Ford ES, Ajani UA, Croft JB, et al. Explaining the decrease in U.S. deaths from coronary disease, 1980-2000. N Engl J Med 2007;356:2388-98.

54. Björck L, Rosengren A, Bennett K, et al. Modelling the decreasing coronary heart disease mortality in Sweden between 1986 and 2002. Eur Heart J 2009;30:1046-56.

55. Piepoli MF, Hoes AW, Agewall S, et al. ESC Scientific Document Group 2016European guidelines on cardiovascular disease prevention in clinical practice: The Sixth Joint Task Force of the European Society of Cardiology and Other Societies on Cardiovascular Disease Prevention in Clinical Practice (constituted by representatives of 10 societies and by invited experts). Developed with the special contribution of the European Association for Cardiovascular Prevention \& Rehabilitation. Eur Heart J 2016;37:2315-81.

56. Mortensen MB, Falk E. Limitations of the SCORE-guided European guidelines on cardiovascular disease prevention. Eur Heart J 2017;38:2259-63.

57. Ambrose JA, Tannenbaum MA, Alexopoulos D, et al. Angiographic progression of coronary artery disease and the development of myocardial infarction. J Am Coll Cardiol 1988;12:56-62.

58. Little WC, Constantinescu M, Applegate RJ. Can coronary angiography predict the site of a subsequent myocardial infarction in patients with mild-to-moderate coronary artery disease? Circulation 1988;78:1157-66.

59. Varenhorst C, Hasvold P, Johansson S, et al. Culprit and Nonculprit Recurrent Ischemic Events in Patients With Myocardial Infarction: Data From SWEDEHEART (Swedish Web System for Enhancement and Development of Evidence-Based Care in Heart Disease Evaluated According to Recommended Therapies). J Am Heart Assoc 2018;7:e007174.

60. Burke AP, Kolodgie FD, Farb A, et al. Healed Plaque Ruptures and Sudden Coronary Death. Evidence That Subclinical Rupture Has a Role in Plaque Progression. Circulation 2001;103:934-40.

61. Vergallo R, Porto I, D'Amario D, et al. Coronary Atherosclerotic Phenotype and Plaque Healing in Patients 
With Recurrent Acute Coronary Syndromes Compared With Patients With Long-term Clinical Stability: An In Vivo Optical Coherence Tomography Study. JAMA Cardiol 2019;4:321-9.

62. ISCHEMIA Trial. ClinicalTrials.gov Identifier: NCT01471522.

63. Hochman JS, Reynolds HR, Bangalore S, et al. Baseline characteristics and risk profiles of participants in the ISCHEMIA randomized clinical trial. JAMA Cardiol 2019;4:273-86.

64. Gibbons RJ. Is the search for enough moderate-to-severe ischemia nearly over? JAMA Cardiol 2019;4:203-5.

65. Boden WE, O'Rourke RA, Teo KK, et al. Optimal medical therapy with or without PCI for stable coronary disease. N Engl J Med 2007;356:1503-16.

66. Bouzas-Mosquera A, Peteiro J, Broullón FJ, et al. Temporal changes in the use and results of exercise echocardiography. Eur Heart J Cardiovasc Imaging 2015;16:1207-12.

67. Jouni H, Askew JW, Crusan DJ, et al. Temporal trends of single-photon emission computed tomography myocardial perfusion imaging in patients without prior coronary artery disease: A 22-year experience at a tertiary academic medical center. Am Heart J 2016;176:127-33.

68. Jouni H, Askew JW, Crusan DJ, et al. Temporal Trends of Single-Photon Emission Computed Tomography Myocardial Perfusion Imaging in Patients With Coronary Artery Disease. A 22-Year Experience From a Tertiary Academic Medical Center. Circ Cardiovasc Imaging 2017;10:e005628.

69. Yeh RW, Mauri L, Wolf RE, et al. Population Trends in Rates of Coronary Revascularization. JAMA Intern Med 2015;175:454-6.

70. Montalescot G, Sechtem U, Achenbach S, et al. 2013 ESC Guidelines on the management of stable coronary artery disease: the task force on the management of stable coronary artery disease of the European Society of Cardiology. Eur Heart J 2013;34:2949-3003.

71. Juarez-Orozco LE, Saraste A, Capodanno D, et al. Impact of a decreasing pre-test probability on the performance of diagnostic tests for coronary artery disease. Eur Heart J Cardiovasc Imaging 2019;20:1198-207.

72. Diamond GA, Forrester JS. Analysis of probability as an aid in the clinical diagnosis of coronary-artery disease. $\mathrm{N}$ Engl J Med 1979;300:1350-8.

73. Reeh J, Therming CB, Heitmann M, et al. Prediction of obstructive coronary artery disease and prognosis in patients with suspected stable angina. Eur Heart J
2019;40:1426-35.

74. Genders TSS, Coles A, Hoffmann U, et al. The external validity of prediction models for the diagnosis of obstructive coronary artery disease in patients with stable chest pain: insights from the PROMISE Trial. JACC Cardiovasc Imaging 2018;11:437-46.

75. Foldyna B, Udelson JE, Karády J, et al. Pretest probability for patients with suspected obstructive coronary artery disease: re-evaluating Diamond-Forrester for the contemporary era and clinical implications: insights from the PROMISE trial. Eur Heart J Cardiovasc Imaging 2019;20:574-81.

76. Baskaran L, Danad I, Gransar H, et al. A comparison of the updated Diamond-Forrester, CAD Consortium and CONFIRM history-based risk scores for predicting obstructive coronary artery disease in patients with stable chest pain: the SCOT-HEART CCTA Cohort. JACC Cardiovasc Imaging 2019;12:1392-400.

77. Knuuti J, Ballo H, Juarez-Orozco LE, et al. The performance of non-invasive tests to rule-in and ruleout significant coronary artery stenosis in patients with stable angina: a meta-analysis focused on post-test disease probability. Eur Heart J 2018;39:3322-30.

78. Marzilli M, Merz CN, Boden WE, et al. Obstructive Coronary Atherosclerosis and Ischemic Heart Disease: An Elusive Link! J Am Coll Cardiol 2012;60:951-6.

79. Stone GW, Hochman JS, Williams DO, et al. Medical Therapy With Versus Without Revascularization in Stable Patients With Moderate and Severe Ischemia. The Case for Community Equipoise. J Am Coll Cardiol 2016;67:81-99.

80. Douglas PS, Hoffmann U, Patel MR, et al. Outcomes of anatomical versus functional testing for coronary artery disease. N Engl J Med 2015;372:1291-300.

81. SCOT-HEART Investigators. CT coronary angiography in patients with suspected angina due to coronary heart disease (SCOT-HEART): an open-label, parallel-group, multicentre trial. Lancet 2015;385:2383-91.

82. Hoffmann U, Ferencik M, Udelson JE, et al. Prognostic value of noninvasive cardiovascular testing in patients with stable chest pain: insights from the PROMISE trial (Prospective Multicenter Imaging Study for Evaluation of Chest Pain). Circulation 2017;135:2320-32.

83. Cheezum MK, Hulten EA, Smith RM, et al. Changes in preventive medical therapies and $\mathrm{CV}$ risk factors after CT angiography. JACC Cardiovasc Imaging 2013;6:574-81.

84. Hwang IC, Jeon JY, Kim Y, et al. Statin therapy is associated with lower all-cause mortality in patients with 
non-obstructive coronary artery disease. Atherosclerosis 2015;239:335-42.

85. Hwang IC, Jeon JY, Kim Y, et al. Association between aspirin therapy and clinical outcomes in patients with nonobstructive coronary artery disease: a cohort study. PLoS One 2015;10:e0129584.

86. Williams MC, Hunter A, Shah AS, et al. Use of coronary computed tomographic angiography to guide management of patients with coronary disease. J Am Coll Cardiol 2016;67:1759-68.

87. Emami H, Takx RA, Mayrhofer T, et al. Nonobstructive coronary artery disease by coronary CT angiography improves risk stratification and allocation of statin therapy. JACC Cardiovasc Imaging 2017;10:1031-8.

88. Ambrose JA. In search of the "vulnerable plaque": can it be localized and will focal regional therapy ever be an option for cardiac prevention? J Am Coll Cardiol 2008;51:1539-42.

89. Alsheikh-Ali AA, Kitsios GD, Balk EM, et al. The vulnerable atherosclerotic plaque: scope of the literature. Ann Intern Med 2010;153:387-95.

90. Raggi P. The never ending search for the elusive vulnerable plaque. Atherosclerosis 2017;263:311-2.

91. Arbab-Zadeh A, Fuster V. The Myth of the "Vulnerable Plaque". Transitioning From a Focus on Individual Lesions to Atherosclerotic Disease Burden for Coronary Artery Disease Risk Assessment. J Am Coll Cardiol 2015;65:846-55.

92. Calvert PA, Obaid DR, O'Sullivan M, et al. Association between IVUS findings and adverse outcomes in patients with coronary artery disease: the VIVA (VH-IVUS in Vulnerable Atherosclerosis) Study. JACC Cardiovasc Imaging 2011;4:894-901.

93. Williams MC, Moss AJ, Dweck M, et al. Coronary Artery Plaque Characteristics Associated With Adverse Outcomes in the SCOT-HEART Study. J Am Coll Cardiol 2019;73:291-301.

Cite this article as: Casolo G, Del Meglio J, Tessa C. Epidemiology and pathophysiologic insights of coronary atherosclerosis relevant for contemporary non-invasive imaging. Cardiovasc Diagn Ther 2020;10(6):1906-1917. doi: 10.21037/ cdt-20-157
94. Bech GJ, De Bruyne B, Pijls NH, et al. Fractional flow reserve to determine the appropriateness of angioplasty in moderate coronary stenosis: a randomized trial. Circulation 2001;103:2928-34.

95. Tonino PAL, De Bruyne B, Pijls NHJ, et al. Fractional flow reserve versus angiography for guiding percutaneous coronary intervention. N Engl J Med 2009;360:213-24.

96. De Bruyne B, Pijls NH, Kalesan B, et al. Fractional flow reserve-guided PCI versus medical therapy in stable coronary disease. N Engl J Med 2012;367:991-1001.

97. Taylor CA, Fonte TA, Min JK. Computational fluid dynamics applied to cardiac computed tomography for non-invasive quantification of fractional flow reserve: scientific basis. J Am Coll Cardiol 2013;61:2233-41.

98. Koo BK, Erglis A, Doh JH, et al. Diagnosis of ischemiacausing coronary stenoses by non-invasive fractional flow reserve computed from coronary computed tomographic angiograms. Results from the prospective multicenter DISCOVER-FLOW (Diagnosis of Ischemia-Causing Stenoses Obtained via Noninvasive Fractional Flow Reserve) study. J Am Coll Cardiol 2011;58:1989-97.

99. Nørgaard BL, Leipsic J, Gaur S, et al. Diagnostic performance of non-invasive fractional flow reserve derived from coronary computed tomography angiography in suspected coronary artery disease: the NXT trial (Analysis of Coronary Blood Flow Using CT Angiography: Next Steps). J Am Coll Cardiol 2014;63:1145-55.

100. Douglas PS, Pontone G, Hlatky MA, et al. Clinical outcomes of fractional flow reserve by computed tomographic angiography-guided diagnostic strategies vs. usual care in patients with suspected coronary artery disease: the prospective longitudinal trial of FFRCT: outcome and resource impacts study. Eur Heart J 2015;36:3359-67.

101.Neumann FJ, Sousa-Uva M, Ahlsson A, et al. 2018 ESC/ EACTS Guidelines on myocardial revascularization. Eur Heart J 2019;40:87-165. 